\title{
Correction to: Comfort Perception Analysis of Human Models Interfacing with Novel Biped-Wheeled-Exoskeletons
}

\author{
Angelica Zoccali and Giovanni Gerardo Muscolo
}

\section{Correction to:}

Chapter "Comfort Perception Analysis of Human Models Interfacing with Novel Biped-Wheeled-Exoskeletons" in: G. Rauter et al. (Eds.): New Trends in Medical and Service Robotics, MMS 93, https://doi.org/10.1007/978-3-030-58104-6_3

In the original version of the book, the following corrections have been incorporated: Table 1 of Chapter 3 has been removed, and the other tables have been renumbered accordingly. The book and the chapter have been updated with the changes. 